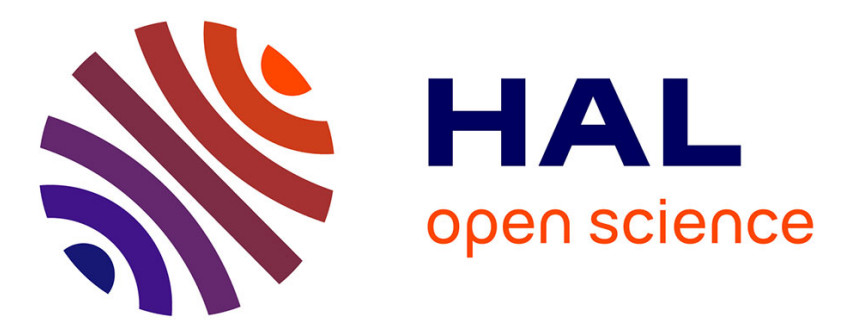

\title{
Thermophysical profile of ethylene glycol based nanofluids containing two types of carbon black nanoparticles with different specific surface areas
}

J. Sobczak, J.P. Vallejo, J. Traciak, S. Hamze, J. Fal, Patrice Estellé, L. Lugo, G. Żyla

\section{To cite this version:}

J. Sobczak, J.P. Vallejo, J. Traciak, S. Hamze, J. Fal, et al.. Thermophysical profile of ethylene glycol based nanofluids containing two types of carbon black nanoparticles with different specific surface areas. Journal of Molecular Liquids, 2021, 326, pp.115255. 10.1016/j.molliq.2020.115255 . hal-03130521

\section{HAL Id: hal-03130521 \\ https://hal.science/hal-03130521}

Submitted on 19 Feb 2021

HAL is a multi-disciplinary open access archive for the deposit and dissemination of scientific research documents, whether they are published or not. The documents may come from teaching and research institutions in France or abroad, or from public or private research centers.
L'archive ouverte pluridisciplinaire HAL, est destinée au dépôt et à la diffusion de documents scientifiques de niveau recherche, publiés ou non, émanant des établissements d'enseignement et de recherche français ou étrangers, des laboratoires publics ou privés. 


\title{
Thermophysical profile of ethylene glycol based nanofluids containing two types of carbon black nanoparticles with different
}

\section{specific surface areas}

Jolanta Sobczak ${ }^{\mathrm{a}}$, Javier P. Vallejo ${ }^{\mathrm{b}}$, Julian Traciak ${ }^{\mathrm{a}}$, Samah Hamze ${ }^{\mathrm{c}}, \mathrm{Jacek}$ Fal $^{\mathrm{a}}$,

Patrice Estelléc $^{\mathrm{c}}$ Luis Lugo ${ }^{\mathrm{b}}$, Gaweł Żyła,* ${ }^{\mathrm{a}, *}$ gyla@prz.edu.pl

${ }^{a}$ Department of Experimental Physics, Rzeszow University of Technology, Rzeszow, Poland

${ }^{\mathrm{b}}$ Departamento de Física Aplicada, Facultade de Ciencias, Universidade de Vigo, Vigo, Spain

${ }^{c}$ LGCGM, University Rennes 1, Rennes, France

\begin{abstract}
The paper summarized results of experimental studies on thermophysical and electrical properties of ethylene glycol based nanofluids containing carbon black nanoparticles. Two types of nanoparticles differing in size and specific surface area were used to develop nanofluids. During examination the thermal conductivity, isobaric heat capacity, mass density, nanofluid-air surface tension, dynamic viscosity, refractive index and electrical conductivity were measured in strict controlled temperature $298.15 \mathrm{~K}$. Obtained results indicate that the specific surface area have great influence on these fundamental properties of nanofluids developed with carbon nanoparticles. Finally, the enhancement of electrical conductivity described in the paper is one of the highest reported for the nanofluids in available literature.
\end{abstract}

Keywords: nanofluid, carbon black, viscosity, thermal conductivity, heat capacity, surface tension

\begin{tabular}{|ll|}
\hline Nomenclature \\
\hline$A$ & constant depending on the reflection plane $[-]$ \\
$B$ & full width at half-maxiumum $(\mathrm{fwhm})[-]$ \\
$c_{p}$ & isobaric heat capacity $\left[\mathrm{kJ} \mathrm{kg}^{-1} \mathrm{~K}^{-1}\right]$ \\
\hline
\end{tabular}

\footnotetext{
${ }^{*}$ Corresponding author

Email address: gzyla@prz .edu.pl (Gaweł Żyła)
} 


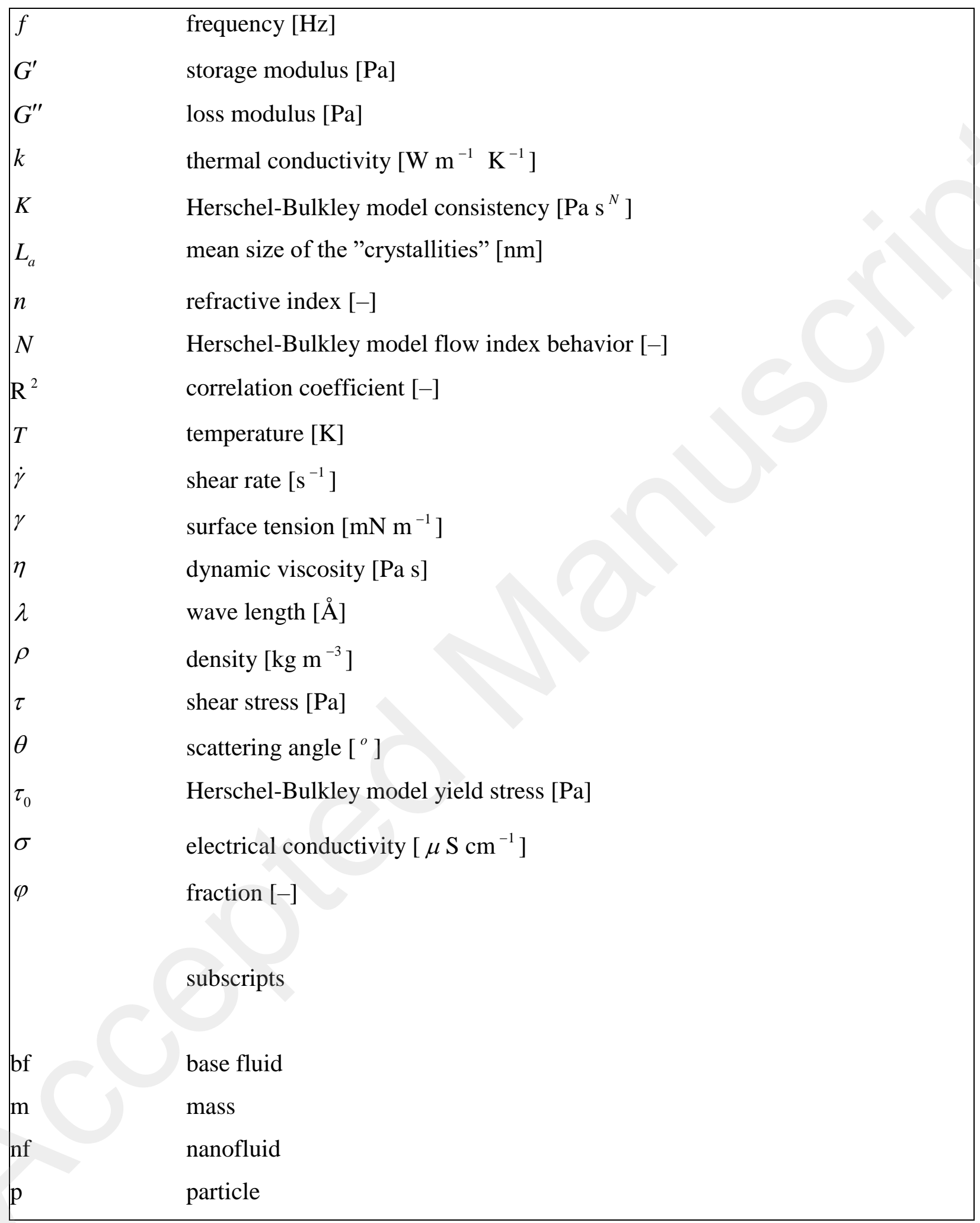

\section{Introduction}


One of the most important factors determining the development of society, science and technology is the efficiency of energy transfer and storage. During last decades it is observed that the energy demand has increased while the impact of the energy sources based on fossil fuels on the natural environment is adverse. Because of that, the needs to exchange "traditional" for renewable energy systems has been emphasized. Among many solutions there is solar energy and well-known collectors. However there is a problem with heat losses and poor heat transfer so this solution required improvements. At a certain point, the idea of replacing the previously used heat transfer fluids with nanofluids was born in order to increase the efficiency of these systems.

Nanofluid is a liquid-solid mixture in which there are dispersed one or various types nanometer-sized particles. One of the first experimental studies on this subject was conducted by Masuda et al. [1]. They analysed thermal properties of system containing $\mathrm{Al}_{2} \mathrm{O}_{3}, \mathrm{SiO}_{2}$ and $\mathrm{TiO}_{2}$ particles in water. The result of their research was the improvement in thermal conductivity for Al ${ }_{2} \mathrm{O}_{3}$-water and $\mathrm{TiO}_{2}$-water, however no increase was observed for $\mathrm{SiO}_{2}$-water [1]. In $1995 \mathrm{Choi}$ and Eastman presented results of their study where the word "nanofluid" appears for the first time [2]. They showed that thermal conductivity of fluid increases when nanoparticles are added to it and suggested many potential benefits for the scientific world in the future. Since then research work in order to find out more about the properties has risen. The current stage of knowledge on the thermo-physical properties of nanofluids can be found in recent review papers $[3,4,5,6,7,8$, $9,10,11,12,13]$. Thermophysical properties and possible applications of nanofluids containing various types of carbon structures have been summarized in Refs. [14, 15, 16]. The review of the papers on lubrication properties of nanofluids containing carbon structures was presented in Ref. [17].

Thermal conductivity of nanofluids with different types of nanoparticles are still the subject of experimental studies. Shamaeil et al. [18] focused on the effects of temperature and volume fraction on the thermal conductivity for double-walled carbon nanotubes (DWCNTs)-ethylene glycol (EG) nanofluids. The results show that thermal conductivity ratio increases with increasing the volume fraction of particle in suspension and temperature. Analysed data also reveals that the maximum enhancement is $24.9 \%$ for $0.6 \%$ volume concentration at 325.15 K. Experimental study of thermal conductivity for nanofluid containing graphene-carbon nanotube (Gr-CNT) hybrid material in ethylene glycol was performed by Trinh et al. The sample with 0.07 vol.\% Gr-CNT at $303.15 \mathrm{~K}$ has $18 \%$ enhancement and in $323.15 \mathrm{~K}-50 \%$ [19]. Harsh et 
al. carried out measurements in which they studied ethylene glycol based nanofluid, with single-walled carbon nanotube (SWNT) using the transient hot wire technique. It was found out that the maximum enhancement is $14.8 \%$ for nanofluid containing $0.21 \%$ volume concentration [20]. Investigation on the thermal properties of diamond-ethylene glycol (DNP-EG) nanofluid was conducted by Yu et al. in Ref [21]. The thermal conductivity enhancement of DNP-EG nanofluids for $1.0 \mathrm{vol} . \%$ at $303.15 \mathrm{~K}$ is up to $17.23 \%$. However, their study has been expanded to observe if thermal conductivity of nanofluids is correlative with $\mathrm{pH}$ values. The data shows that $\mathrm{pH}$ value has a direct effect on the stability of the samples - according to the measurements for DNP-EG nanofluids when $\mathrm{pH}$ is above value of 8.5, no sedimentation is observed within 6 months [21].

In the last years, nanofluids have achieved attention in terms of thermal conductivity studies. However properties such as viscosity of nanofluids containing carbon nanoparticles was also experimental studied. Yu et al. has conducted measurements of diamond nanoparticles in ethylene glycol at $303.15 \mathrm{~K}$ [21]. The data depicts that with the increase of temperature, the viscosity of nanofluids decreases rapidly. His conclusions demonstrates Newtonian behaviour due to linear relation between shear stress and shear rate.

On the other hand oscillatory measurements at $298.15 \mathrm{~K}$ carried out for ethylene glycol based graphite/dimaonds mixture nanofluids shows that it behaves like non-Newtonian fluid [22]. Similary the rheology results of EG-based nanofluid with single-walled carbon nanohorn presents that it has non-Newtonian shear thinning behaviour at higher nanohorn loading [23]. Recently Żyła presented results of the experimental study on the rheological behavior of ethylene glycol based nanofluids containing low concentrations (up to $1 \mathrm{wt} . \%$ ) of carbon black nanoparticles [24]. He showed that these materials exhibit non-Newtonian viscoelastic nature.

Among all of these properties heat capacity and mass density of EG based nanofluids are also the subject of experimental studies. However most of the papers concern oxides and nitrides $[25,26,27,28,29]$, while results on the ethylene glycol based nanofluids containing carbon nanostructures are rare. The isobaric heat capacity and mass density of EG based nanofluids containing nanodiamonds with different purities were experimentally investigated by us previously and presented elsewhere [30]. We have presented that classical models described these properties with good accuracy.

Recent results of the studies on the surface tension of EG based nanofluids starts to earn interest $[31,32,33]$. According to the best authors knowledge the surface tension of nanofluids 
containing carbon nanoparticles with ethylene glycol as base fluid was not experimentally studied before.

Despite the great interest in the thermophysical properties of nanofluids containing various types of carbon based nanoparticles, there are only few papers, which reports their electrical properties. Żyła et al. [30] investigated electrical conductivity of nanodiamonds ethylene glycol nanofluids. They prepared nanofluids with two types of nanodiamond nanoparticles with different level of purity (87\% - ND87, 97\% - ND97). Five samples show nonlinear increase in electrical conductivity with increasing volume fraction, and the maximum value was achieved at 0.0338 volume fraction. They also noticed that there is no visible difference between nanofluids containing nanodiamonds with various purities. Different types of nanofluid based on carbon based materials and ethylene glycol were also investigated by Żyła et al. [22]. This time, they used two types of graphite and diamond mixtures, with different ash content, to prepare ethylene glycol based nanofluids. The five samples with volume fraction between 0.004-0.023 were prepared for both type of nanoparticles. Obtained results show nonlinear increase in electrical conductivity with increasing volume fraction for both types of nanofluids. They also revealed that ash content has a significant impact on the electrical conductivity of such types of nanofluids. Nanofluids prepared with nanoparticles with a higher content of ash are less electrically conductive. The maximum electrical conductivity enhancement was noted for the nanofluid with lower ash content and it was almost 200 times greater than that for pure ethylene glycol and 10 times higher than that with higher ash content at the same volume fraction.

In this paper results of the experimental studies on thermal conductivity, heat capacity, viscosity, mass density, surface tension, refractive index and electrical conductivity of nanofluids containing two different types of carbon black nanoparticles are presented.

\section{Materials and methods}

In the following sections the description of materials and methods used in this study is presented. The information about the measuring equipment together with the uncertainty determination are also reported.

\subsection{Nanoparticle characterization}

In this study two different types of carbon black nanoparticles were used. Both of them are 
commercially available, and are labeled in this paper as CB1 (Degussa AG (Hanau-Wolfgang, Germany)), and CB2 (PlasmaChem GmbH (Berlin, Germany)). The properties of the used materials has been summarized in Table 1 .

Table 1: Basic properties of the carbon black nanoparticles used in the study.

CB1

Manufacturer

Deagussa AG

Appearance

black powder

Ash content

$\leq 2,0 \%$

CAS No.

$7782-40-3$

Average particle size

$30 \mathrm{~nm}$

BET Surface Area ${ }^{\dagger}$

$1000 \mathrm{~m}^{2} \mathrm{~g}^{-1}$

BET Surface Area

$1012 \pm 4 \mathrm{~m}^{2} \mathrm{~g}^{-1}$

CB2

Manufacturer

PlasmaChem

Appearance

black powder

Ash content

$<0,02 \%$

CAS No.

$7782-40-3$

Average particle size

ca. $13 \mathrm{~nm}$

Specific surface area ${ }^{\dagger}$

ca. $570 \pm 20 \mathrm{~m}^{2} \mathrm{~g}^{-1}$

BET Surface Area

$450 \pm 8 \mathrm{~m}^{2} \mathrm{~g}^{-1}$

To evaluate the size and shape of the nanoparticles, series of scanning electron microscopy (SEM) pictures were taken with JEOL JSM-6700F field emission scanning electron microscope (JEOL, Tokyo, Japan). Figure 1 presents SEM pictures of the used carbon black nanoparticles with different magnifications. The declared size of the nanoparticles, presented in Table 1, was confirmed there. 
Figure 1: Scanning electron microscope (SEM) pictures of dry nanoparticles: A) and B) present CB1 (Degussa AG (Hanau-Wolfgang, Germany)) nanoparticles with different magnification, C) and D) show CB2 (PlasmaChem GmbH (Berlin, Germany)) with different magnification.

The energy-dispersive X-ray spectroscopy microanalysis (EDS) was performed with Inca Energy 300 (Oxford Instruments, Oxford, UK) coupled to the previous described SEM. The EDS spectrum of the used nanopowders were presented in Fig. 2. Performed measurements confirm the chemical structure of carbon (C), as expected for these nanomaterials. The appearance of the silica (Si) peak can be explained by the physical support over which the analyzes were performed.

Figure 2: A) and C) the scanning electron microscope pictures of observed area of CB1 (Degussa AG (Hanau-Wolfgang, Germany)) and CB2 (PlasmaChem GmbH (Berlin, Germany)) respectively. B) and D) energy-dispersive X-ray spectroscopy microanalysis spectra of CB1 and CB2 carbon black nanopowders respectively.

Powder X-ray diffraction experiments were performed on a Bruker D8 Advance (Bruker $\mathrm{GmbH}$, Karlsruhe, Germany) diffractometer working in a $\theta-2 \theta$ modified Bragg-Brentano geometry and equipped with a LynxEye fast detector. The $\mathrm{Cu} \mathrm{A} \alpha 1$ radiation $(\lambda=1.5406 \AA)$ is selected using a $\mathrm{Ge}(111)$ monochromator. The 5-90 $2 \theta$ angular domain was scanned with a step size of $0.02^{\circ}$ and integration time of 895 s per step. A misoriented single crystalline $\mathrm{Si}$ sample holder was used to avoid any background signal from it.

Both samples show similar XRD profiles which are typical of the carbon black with two main Bragg diffraction peaks for the (002) and (110) reflections at $2 \theta$ ca. $24.5^{\circ}$ and $24.6^{\circ}$ and ca. $43.6^{\circ}$ and $43.2^{\circ}$ for CB2 and CB1, respectively as presented in Fig. 3. After subtracting a baseline, the peaks were fitted with Gaussian curves and the Scherrer equation (eq. 1) was used to calculate the mean size $L_{a}$ of the 'crystallites' of the two samples:

$$
L_{a}=\frac{A \lambda}{B \cos \theta},
$$

where $A$ is a constant depending on the reflection plane 0.9 and 1.84 for the 002 and 110 reflections, respectively, $\lambda$ is the XRD wavelength, $\theta$ is the scattering angle (in radians), and 
$B$ is the full width at half-maximum (fwhm). For both samples studied, $L_{a}$ is less than $1 \mathrm{~nm}$ in agreement with the board XRD features shown in Fig. 3 and the disordered structure expected for carbon black particles.

Figure 3: X-Ray diffractogram for the nanopowders used in this study. Black line refers to the CB1 (Degussa AG (Hanau-Wolfgang, Germany)) nanoparticles and gray to the CB2 (PlasmaChem GmbH (Berlin, Germany)).

The Brunauer-Emmet-Teller (BET) specific surface area of both carbon black nanopowders was determined from nitrogen physisorption with a Micromeritics Gemini VII 2390t instrument using a mixture of $\mathrm{N}_{2} / \mathrm{He}(30 \% / 70 \%)$. To avoid the surface hydration, samples were previously outgassed under vacuum at $323.15 \mathrm{~K}$.

The BET surface area of CB1 is experimentally evaluated to $1012 \pm 4 \mathrm{~m}^{2} \mathrm{~g}^{-1}$, which is in good agreement with manufacturer data as the deviation is $1.2 \%$. For CB2, the measured BET value is $450 \pm 8 \mathrm{~m}^{2} \mathrm{~g}^{-1}$ that is lower by $21 \%$ than the manufacturer data. These measurements clearly demonstrate that the carbon black nanopowders present distinct BET surface area.

\subsection{Sample preparation}

There are two methods in which a nanofluid could be prepared: (a) single step and (b) two-step preparation process. The single step method involves the direct production of nanoparticles in a base liquid and can be completed in various ways. For example by reducing the compound in the presence of another substance under microwave irradiation, a nanoparticle-source evaporation and deposition of the evaporant into a base fluid, and sonication and using the vacuum-SANSS (submerged arc nanoparticle synthesis system). Samples can also be prepared based on two-step method by dispersing the dry particles within the base fluid. Taking into account fact that preparing dry nanoparticles is often easy and cheap process, and nanoparticles are commercially available this method seems to be more attractive for potential application, which demands a large-scale production process. However two-step method has some drawback, e.g some types of nanoparticles easily aggregate and sediment because of strong van der Walls force between particles and gravity. In the present study two types of carbon black 
nanoparticles were used to prepare nanofluids with two-step method. Both nanopowders (with two different specific surface area, ash content and sizes) were purchased commercially and their specification is presented in the Table 1 . In the first stage of sample preparation nanoparticles were weighed on an analytical balance. After that the base fluid - ethylene glycol (EG) produced by Fisher Chemical (Loughborough, UK) with the purity over 99\%, was added in order to achieve desired concentration of the particles in the suspension. For the dispersion nanoparticles, mechanical mixing and ultrasonic bath were used. Sonication is well known method of dispersing nanoparticles, as it was described in recent review paper [34]. No surfactants were used during sample preparation.

\subsection{Stability characterization}

After preparation of the samples, the stability of these type of nanofluids was evaluated. The high light absorbance of nanofluids containing carbon black nanoparticles and its high viscosity make it impossible to precise the determination of the stability of samples containing the same fraction of particles that were used in the study of thermophysical properties. The stability evaluation of these nanofluids was performed on diluted samples containing $0.02 \mathrm{wt} \%$ of particles.

One of the popular methods of the stability determination of nanofluids is measuring its Zeta potential as it was described in Ref. [35]. The Zeta potential of the CB-EG nanofluids was measured with Zetasizer Nano ZS device (Malvern Instruments Ltd, Malvern, UK) at 298.15 K. The values obtained in this study were $+57 \pm 6 \mathrm{mV}$ and $-110 \pm 4 \mathrm{mV}$ for nanofluids containing $\mathrm{CB} 1$ and CB2, respectively. Nanofluids with absolute Zeta potential value higher than $60 \mathrm{mV}$ are consider as very stable [35], however one must note that this method could not be fully reliable for ethylene glycol based nanofluids, therefore another type of stability examination was also performed.

The Dynamic Light Scattering (DLS) method allows the apparent size distribution of nanoparticles in suspension to be determined. This method was used with Zetasizer Nano ZS device (Malvern Instruments Ltd, Malvern, UK) for $0.02 \mathrm{wt}$ \% nanofluids at $298.15 \mathrm{~K}$ and using a scattering angle value $173^{\circ}$. Samples were analyzed just after preparation $(0 \mathrm{~h})$ and 2, 6, 24 and 48 $\mathrm{h}$ later under static conditions. It should be noted that the size value by DLS measurements is assumed as the diameter of a perfect sphere with a translational diffusion coefficient equivalent to 
that of the dispersed particle. Thus, these values are usually referred to hydrodynamic diameter or apparent size. Consequently, it should be taken into account that the stability analysis is focused on the temporal evolution of the DLS measurements rather than the values of the sizes themselves. Figure 4 presents obtained results. One could note that the apparent size of CB1 nanoparticles is two times higher that CB2 nanoparticles and it corresponds with the manufacturer declaration and SEM pictures. Nanofluids containing CB2 nanoparticles tend to agglomerate after 48 hours, however dispersion for samples with CB1 nanoparticles is stable with time during measurement. The apparent size distribution analysis presented in Fig. 4A) and Fig. 4B), show similar profiles for both samples, CB1 and CB2 nanofluids, along the observed time (2 days). Nevertheless results collected for CB1-EG sample show a low intensity peak around $0.5 \mu \mathrm{m}$ that appears $24 \mathrm{~h}$ after preparation and increases after $48 \mathrm{~h}$. On the other hand, the CB2-EG nanofluid shows a similar small peak for the first time $48 \mathrm{~h}$ after preparation. These peaks reveal symptoms of agglomeration of nanoparticles that is occurring within the fluids, which is stronger and faster for the nanofluid containing CB1 nanoparticles.

Finally, the possible occurence of sedimentation was not being observed until several hours after preparation of the samples that were studied. Therefore, taking into account all these factors, the examined nanofluids were thermophysically studied for the few hours after samples preparation, in conditions of stable dipersions.

Figure 4: Results of dynamic light scattering (DLS) examination of the apparent size of particles in ethylene glycol based nanofluids containing 0.02 wt.\% carbon black nanoparticles. A) and B) Apparent size distribution for nanofluids containing CB1 and CB2 nanoparticles, respectively; different colors refers to time after preparation of the samples. C) Average Z-size as a function of time after preparation of the samples for the CB1-EG ( ) and CB2-EG ( ) nanofluids at 298.15 $\mathrm{K}$; dotted lines indicate the value after preparation $(0 \mathrm{~h})$.

\subsection{Methods}

Thermal conductivities of the base fluid - ethylene glycol and the elaborated nanofluids were measured at $298.15 \mathrm{~K}$ by means of a THW-L2 thermal conductivity device (Thermtest Inc., Canada) based on the transient short hot wire (THW) technique, that was already used in examination of nanofluids $[36,37,38]$. The THW-L2 apparatus allows obtaining direct thermal 
conductivity data of liquids in agreement with ASTM D7896-14 standard [39]. This device is coupled with an EchoTerm Dry Bath which maintains the sample at the test temperature. The wire welded in a sensor has a length of $60 \mathrm{~mm}$ with a diameter of $0.1 \mathrm{~mm}$. It is vertically inserted in the sample, and the whole set is introduced in the dry bath. Before starting the measurements, the used software performs a power test for each family of fluids under study and from this test, a heating power and a short power input time are selected avoiding natural convection phenomena in the measurements. Five measurements were carried out to ensure the repeatability of the experimental values, the duration of each measurement being 10 seconds. The declared accuracy in thermal conductivity values by the manufacturer is $5 \%$.

Experimental isobaric heat capacities for CB-EG nanofluids were determined by a quasi-isothermal temperature modulated differential scanning calorimetry technique. For this purpose, a differential scanning calorimeter, Q2000 (TA Instruments, New Castle, USA) was used at $298.15 \mathrm{~K}$ as measurement temperature. Samples are housed into $\mathrm{T}_{\text {zero }}$ aluminum pans and weighted before and after performing the tests to validity the measurement. Sinusoidal temperature modulations around the studied temperatures were selected to obtain the isobaric heat capacities. More details about the $c_{p}$ determination by using this device were previously reported $[28,40]$, the total relative uncertainty being lower than $3 \%$.

The mass density of the investigated nanofluid was determined using an automatic oscillating U-tube densitymeter DMA 4100M (Anton Paar, Graz, Austria). The sample was inserted into a U-shaped borosilicate glass tube and constant temperature $298.15 \mathrm{~K}$ was maintained. Three series of measurements were carried out, ten measurements in each series. The uncertainty of the values obtained with this equipment was determined on the base of (a) the deviation between the experimental data and the corresponding value in the literature and (b) standard deviation of one hundred measuring points distilled water at $298.15 \mathrm{~K}$. For these one hundred measurements, the obtained mass density of water was $0.9969 \mathrm{~g} \mathrm{~cm}^{-3}$ with standard deviation $0.0002 \mathrm{~g} \mathrm{~cm}^{-3}$. According to the literature [41], the water density is $0.997066 \pm$ $0.000001 \mathrm{~g} \mathrm{~cm}^{-3}$. Considering the literature values and the obtained experimental results the relative uncertainty of mass density measurements could be declared as $0.1 \%$.

Surface tension between air and nanofluid measurements were performed with Drop Shape Analyzer DSA25 (KRÜSS GmbH, Hamburg, Germany). This equipment uses the analysis of the 
shape of the drop and based on the Young-Laplace equation allows to determine the surface tension of the fluid. In order to measure surface tensions of nanofluids a drop "hang" for 10 minutes to equalize nanofluids temperature with ambient air temperature. After such stabilization the surface tension of a droplet was measured. To obtain reliable results after each measurement a drop was dropped and another one was produced with the waiting time for temperature stabilization. The experimental study included three series of measurements that followed each other. Environmental chamber (KRÜSS GmbH, Hamburg, Germany) allows to perform measurements in strict controlled temperature, $298.15 \mathrm{~K}$. Relative uncertainty of obtained surface tension values was estimated as $1 \%$ as presented elsewhere $[31,33]$.

The equipment used to perform the rheological properties examination was a rheometer HAAKE MARS 2 (Thermo Electron Corporation, Karlsruhe, Germany). Two types of measurements were performed: (a) the rotational tests in control rate mode, and (b) the oscillatory tests at constant oscillation frequency $1.0 \mathrm{~Hz}$. Taking into account fact that CB-EG nanofluids exhibit a non-Newtonian character, as presented in previous study [24], the cone-plate measuring geometry was used; the diameter of the rotor is $60 \mathrm{~mm}$, and cone angle is $2^{\circ}$. Constant temperature of the sample, $298.15 \mathrm{~K}$, was maintained by the Peltier system coupled with a Phoenix 2 thermostat (Thermo Electron Corporation, Karlsruhe, Germany); this system allows to keep the temperature of the sample with the accuracy of $0.1 \mathrm{~K}$. Rotational measurements were performed at shear rate range from $0.1 \mathrm{~s}^{-1}$ to $1000.0 \mathrm{~s}^{-1}$ and oscillatory tests in deformation range from $0.1 \%$ (0.001) to $1000.0 \%$ (10.000). The step of shear rate and deformation increases was planned on the logarithmic scale. This measuring system was previously used, therefore more detailed description of the uncertainty discussion could be find elsewhere [30, 42].

The refractive index was measured with the Refractometer Abbemat 550 (Anton Paar OptoTec GmbH, Seelze-Letter, Germany). A $500 \mu \mathrm{L}$ sample was placed in the refractometer using the HTL Discovery Comfort DV1000 single channel pipette (HTL Lab Solutions, Warsaw, Poland) with an accuracy of volume of $0.5 \%$. The sample temperature was stabilized at $298.15 \mathrm{~K}$ with an accuracy of $0.03 \mathrm{~K}$ for 5 minutes. The refractive index value was determined as the average of a series of three measurements performed for various samples. The relative uncertainty of measurement of refractive index performed at this station was determined at less than $1 \%$ of the measured value, as shown in Ref. [43].

The electrical conductivity of carbon black ethylene glycol was measured with MultiLine 
3410 conductivity meter (WTW GmbH, Weilheim, Germany) working with conductivity probe TetraCone 925 (WTW GmbH, Weilheim, Germany). Measurement was performed for 10 minutes, at constant temperature $298.15 \mathrm{~K}$ with $0.2 \mathrm{~K}$ accuracy. The value of electrical conductivity was obtained as the average value. The temperature was stabilized at least 10 minutes before measurement. Relative uncertainty of this measuring setup was evaluated to $1 \%$ of the measured value as presented in Ref. [42].

\section{Results and discussion}

In the following subsections the obtained results have been presented along with the discussion and graphic representation.

\subsection{Thermal conductivity}

The experimental value of atmospheric pressure thermal conductivity of ethylene glycol at 298.15 K, Table 2, agrees well with those of Lide [44], with a deviation of $-2.2 \%$, Akilu et al. [45], with a deviation of $-1 \%$, and $\dot{Z} y \nmid$ a et al. [30], with an agreement of $+1.8 \%$. As it can be observed, these deviations are lower than uncertainty in thermal conductivity measurements.

Results of experimental study on the thermal conductivity, $k$, of CB1-EG and CB2-EG nanofluids were summarized in Table 2 and presented in Fig. 5, where it is shown how does the value of thermal conductivity change with increasing mass fraction of nanoparticles. The picture depicts that the highest enhancement of thermal conductivity (4.8\%) was observed for nanofluids containing CB1 nanoparticles with the highest examined mass concentration 2 wt.\%. Additionally it was presented that the dependence of the thermal conductivity on the mass fraction of these materials could be modeled with linear function:

$$
\frac{k_{n f}}{k_{b f}}=1+2.42 \varphi_{m},
$$

where $k$ is thermal conductivity, $\varphi$ is fraction, and subscripts $n f, b f, m$ stands for nanofluid, base fluid and mass respectively. In the case of the fitting the linear function (2) to the experimental data the coefficient of determination $R^{2}=1$.

Thermal conductivity for the second type of investigated nanofluids is definitely lower than in case of CB1-EG nanofluids. The enhancement comparing with the pure ethylene glycol is 
approximately $1 \%$. Results of the experimental study of thermal conductivity of CB2-EG nanofluids could be also modeled with linear function in form of:

$$
\frac{k_{n f}}{k_{b f}}=1+0.69 \varphi_{m} .
$$

Table 2: Experimental values of the thermal conductivity, $k_{n f}$, of CB-EG nanofluids at $298.15 \mathrm{~K}$.

\begin{tabular}{|l|ll|ll|} 
& CB1-EG & \multicolumn{2}{l|}{ CB2-EG } \\
\hline$\varphi_{m}$ & $k_{n f}$ & $k_{n f} / k_{b f}$ & $k_{n f}$ & $k_{n f} / k_{b f}$ \\
\hline & $\mathrm{W} \mathrm{m}^{-1} \mathrm{~K}^{-1}$ & - & $\mathrm{W} \mathrm{m}^{-1} \mathrm{~K}^{-1}$ & - \\
\hline 0.000 & 0.248 & 1.0000 & 0.248 & 1.0000 \\
0.005 & 0.251 & 1.0121 & 0.250 & 1.0081 \\
0.010 & 0.254 & 1.0242 & 0.250 & 1.0081 \\
0.020 & 0.260 & 1.0484 & 0.251 & 1.0121 \\
\hline
\end{tabular}

Figure 5: Dependence of thermal conductivity, $k$, and thermal conductivity ratio, $k_{n f} / k_{b f}$, on the mass fraction, $\varphi_{m}$, of the particles for the CB1-EG (०) and CB2-EG (•) nanofluids at $298.15 \mathrm{~K}$. Points represent experimental data, dotted and solid line - linear function (2) and (3) respectively.

The first type of carbon black nanopowder has approximately two times greater value, it is $1012 \pm 4 \mathrm{~m}^{2} \mathrm{~g}^{-1}$ and $450 \pm 8 \mathrm{~m}^{2} \mathrm{~g}^{-1}$ for CB1 and CB2 respectively. Furthermore the average particle size which is grater for the first type can contribute to better thermal conductivity for this nanofluid. The effect of particle size on the thermal conductivity was analyzed for alumina nanofluids where diameter in the range from 8 to $282 \mathrm{~nm}$ was taken [46]. Beck et al. came to the conclude that the thermal conductivity decreases as the particle size is below value of $50 \mathrm{~nm}$. The improvement in the thermal conductivity due to the increasing specific surface area (SSA) is well recognized in the literature. From the results by studying carbon nanofluids [47, 48, 49, 50, 51], it was found as higher thermal conductivity belongs to carbon-based nanoadditives with higher specific surface area. Nowadays, it is extensively recognized that the presence of a nanolayer at the solid-liquid interface and nanoparticle aggregation entails the main way for thermal conductivity enhancement in nanofluids. The liquid molecules close to particle surfaces allow the formation of layered structures and act much like a solid [47]. Therefore, the dimension (thickness) of the 
interfacial layer has a noticeable effect on the enhanced thermal conductivity of the carbon-based nanofluids [48]. Thus, nanoadditives with higher specific surface area lead to decreases on the contact resistance, and consequently superior thermal conductivity enhancements [47, 49]. In addition, it should be noted that all surfaces measured with BET measurement in equilibrated suspensions will acquire layers of fluid molecules that will behave as an interfacial phase [50]. Suspended nanoparticles can form larger agglomerates through the solid/liquid/solid interface, but volume and contribution of the interfacial phase will always remain proportional to the total surface area of dry powders. Thus, the microscopic properties corresponding to the SSA values for the $\mathrm{CB} 1$ and $\mathrm{CB} 2$ nanopowders correlate to the macroscopic effect in the thermal conductivity enhancements of the nanofluids. Thermal conductivity is superior in nanofluids with larger nanoparticle surface area, CB1-EG.

\subsection{Isobaric heat capacity}

The experimental isobaric heat capacity value for EG at $298.15 \mathrm{~K}$, presented in Table 3, is in good agreement with literature data $[52,53,54,55,29]$. Deviations of $+0.1 \%,+0.6 \%,+0.8 \%$, $+0.4 \%$ and $-1.4 \%$ were obtained with respect to the values from Nikolaev and Rabinovich [52], Murthy and Subrahmanya [53], Stephens and Tamplin [54], Zaripov [55], and Ż yła et al. [29], respectively.

Figure 6: Dependence of heat capacity, $c_{p}$, and heat capacity ratio, $c_{p, n f} / c_{p, b f}$, on the mass fraction, $\varphi_{m}$, of the particles for the CB1-EG (•) and CB2-EG (०) nanofluids at 298.15 K. Points represent experimental data, solid lines - equation (4).

Table 3: Experimental values of the isobaric heat capacity, $c_{p, n f}$, of CB-EG nanofluids at 298.15 $\mathrm{K}$.

\begin{tabular}{l|ll|ll} 
& CB1-EG & & \multicolumn{2}{l}{ CB2-EG } \\
\hline$\varphi_{m}$ & $c_{p, n f}$ & $c_{p, n f} / c_{p, b f}$ & $c_{p, n f}$ & $c_{p, n f} / c_{p, b f}$ \\
- & $\mathrm{kJ} \mathrm{kg}^{-1} \mathrm{~K}^{-1}$ & - & $\mathrm{kJ} \mathrm{kg}^{-1} \mathrm{~K}^{-1}$ & - \\
\hline 0.000 & 2.424 & 1.0000 & 2.424 & 1.0000 \\
\cline { 2 - 4 } & &
\end{tabular}




\begin{tabular}{l|ll|ll}
0.005 & 2.383 & 0.9831 & 2.399 & 0.9893 \\
0.010 & 2.357 & 0.9724 & 2.371 & 0.9777 \\
0.020 & 2.302 & 0.9497 & 2.311 & 0.9530 \\
\hline
\end{tabular}

The experimental results for the different-loaded CB-EG nanofluids are presented in Table 3. It can be observed that the isobaric heat capacity decreases slightly with the increasing fraction of both CB nanoparticles. These decreases reach $5.0 \%$ and $4.6 \%$ for the nanofluids with the highest examined $\mathrm{CB} 1$ and $\mathrm{CB} 2$ concentration, respectively. The literature about nanofluids evidenced different effects in the isobaric heat capacity of the base fluid by the dispersion of nanoadditives. According to Riazi et al. [56], when the base fluid is water or a glycol, it tends to decrease with the increasing nanoadditive loading. Nevertheless, it is usual to observe increases in the isobaric heat capacity of nanofluids based on molten salts or ionic liquids caused by the nanoparticle addition. Therefore, our reported experimental behaviour in Fig. 6 is in accordance with the described behaviours for glycol-based nanofluids.

The decreases caused by the addition of $\mathrm{CB} 1$ and $\mathrm{CB} 2$ are similar among them, $0.7 \%$ being the maximum deviation. Likewise, systematic lower values appear by the dispersion of $\mathrm{CB} 1$, the nanoadditive with higher specific surface area. The correlation from Xuan and Roetzel [57, 30] describes the isobaric heat capacity of nanofluids on the basis of the mass fraction of nanoparticles in the dispersion:

$$
c_{p, n f}=\varphi_{m} c_{p, p}+\left(1-\varphi_{m}\right) c_{p, b f},
$$

were $c_{p}$ is the specific heat capacity, $\varphi_{m}$ is the nanoadditive mass fraction and subscripts $n f$, $p$ and $b f$ stand for nanofluid, nanoparticles and base fluid, respectively.

Experimental isobaric specific heat capacities of $1.017 \mathrm{~kJ} \mathrm{~kg}^{-1} \mathrm{~K}^{-1}$ and $1.148 \mathrm{~kJ} \mathrm{~kg}^{-1} \mathrm{~K}$ ${ }^{-1}$ were obtained for the CB1 and CB2 raw nanopowders at $298.15 \mathrm{~K}$. The heat capacity of CB1 is slightly lower than that of $\mathrm{CB} 2$, which contributes to further reducing the heat capacity of the base fluid in which it is dispersed, as indicated above. Deviations between experimental and predicted values by using these experimental values here reported as $c_{p, p}$ are lower than $4 \%$. Likewise, the $c_{p, p}$ is usually taken in the literature as the value of the heat capacity for the bulk material [29]. Taking into account the reported $c_{p}$ value of $0.716 \mathrm{~kJ} \mathrm{~kg}^{-1} \mathrm{~K}^{-1}$ for amorphous carbon by 
Takahashi and Westrum [58] or $0.770 \mathrm{~kJ} \mathrm{~kg}^{-1} \mathrm{~K}^{-1}$ for dense graphite by Lutcov et al. [59], deviations between experimental and predicted values for the 0.005 and 0.010 nanoadditive mass fractions lower than $2.2 \%$ are obtained. For the highest nanoadditive mass concentration the deviation increases up to $3.7 \%$.

\subsection{Mass density}

Table 4 shows the obtained experimental results of mass density measurements for two different nanofluids at $298.15 \mathrm{~K}$. The density measurement of the base fluid is highly consistent with our previous work [30] with a deviation less than $0.02 \%$. In Fig. 7, a clear increase in the density of the nanosuspension can be observed as the mass fraction of the nanoparticles increases. No significant differences between mass density values of CB1-EG and CB2-EG were noted.

Table 4: Experimental values of the mass density, $\rho_{n f}$, of CB-EG nanofluids at $298.15 \mathrm{~K}$.

\begin{tabular}{l|ll|ll} 
& CB1-EG & & CB2-EG \\
\hline$\varphi_{m}$ & $\rho_{n f}$ & $\rho_{n f} / \rho_{b f}$ & $\rho_{n f}$ & $\rho_{n f} / \rho_{b f}$ \\
- & $\mathrm{g} \mathrm{cm}^{-3}$ & - & $\mathrm{g} \mathrm{cm}^{-3}$ & - \\
\hline 0.000 & 1.1095 & 1.0000 & 1.1095 & 1.0000 \\
0.005 & 1.1121 & 1.0023 & 1.1099 & 1.0004 \\
0.010 & 1.1137 & 1.0038 & 1.1134 & 1.0035 \\
0.020 & 1.1156 & 1.0055 & 1.1189 & 1.0085 \\
\hline
\end{tabular}

Figure 7: Dependence of mass density, $\rho$, and mass density ratio, $\rho_{n f} / \rho_{b f}$, on the mass fraction, $\varphi_{m}$, of the particles for the CB1-EG (०) and CB2-EG (•) nanofluids at $298.15 \mathrm{~K}$.

\subsection{Surface tension}

Results of experimental study on the surface tension, $\gamma$, of CB1-EG and CB2-EG based nanofluids were summarized in Table 5. The value of surface tension decreases for both nanofluids with increasing mass fraction of nanoparticles as it is presented on graph in Fig. 8. 
Table 5: Experimental values of the surface tension, $\gamma_{n f}$, of CB-EG nanofluids at $298.15 \mathrm{~K}$.

\begin{tabular}{l|ll|ll} 
& CB1-EG & & CB2-EG \\
\hline$\varphi_{m}$ & $\gamma_{n f}$ & $\gamma_{n f} / \gamma_{b f}$ & $\gamma_{n f}$ & $\gamma_{n f} / \gamma_{b f}$ \\
- & $\mathrm{mN} \mathrm{m}^{-1}$ & - & $\mathrm{mN} \mathrm{m}^{-1}$ & - \\
\hline 0.000 & 47.53 & 1.0000 & 47.53 & 1.0000 \\
0.005 & 46.92 & 0.9872 & 47.83 & 1.0063 \\
0.010 & 45.57 & 0.9588 & 47.12 & 0.9914 \\
0.020 & 39.76 & 0.8365 & 46.25 & 0.9731 \\
\hline
\end{tabular}

Figure 8: Dependence of surface tension, $\gamma$, and surface tension ratio, $\gamma_{n f} / \gamma_{b f}$, on the mass fraction, $\varphi_{m}$, of the particles for the CB1-EG (०) and CB2-EG (•) nanofluids at 298.15 K. Points represent experimental data, dotted and solid line - linear function (5) and (6) respectively.

Based on these results it can be concluded, that the surface tension of the CB1-EG is decreasing more significantly that in case of CB2-EG. On the base of the results presented in Fig. 8 one might note that the surface tension of nanofluids with mass concentration $2 \mathrm{wt} . \%$ is $39.76 \mathrm{mN}$ $\mathrm{m}^{-1}$ and $46.25 \mathrm{mN} \mathrm{m}^{-1}$ for CB1 and CB2 respectively. Experimental data could be modeled with linear functions, as follow:

$$
\begin{aligned}
& \frac{\gamma_{n f}}{\gamma_{b f}}=1-7.14 \varphi_{m}, \\
& \frac{\gamma_{n f}}{\gamma_{b f}}=1-1.13 \varphi_{m},
\end{aligned}
$$

for CB1-EG and CB2-EG respectively. The coefficient of determination $R^{2}=1$ for both fitted curves.

The difference in surface tension could be related to average particle size which value for $\mathrm{CB} 1$ is almost twice higher than for CB2. Similar conclusions were obtained in [60], where Chinnam et al. were analyzing the surface tension of four types of nanofluids in base fluid of $60 \%$ propylene glycol and $40 \%$ water by mass. On the other hand it should be noted that the specific surface area of CB1 is also two times higher that in case of CB2, which could affect the surface tension. 


\subsection{Dynamic viscosity}

Dependence of the shear stress and dynamic viscosity on the shear rate of both examined nanofluids has been presented in Fig. 9. Both, CB1-EG and CB2-EG nanofluids exhibit a non-Newtonian shear thinning behavior. Similar nature of ethylene glycol based nanofluids containing carbon structures (nanohorns, graphite/diamond mixture, nanodiamonds) has been already presented in literature $[23,22,30]$. One might note that this kind of behavior could be modeled with Herschel-Bulkley (H-B) model as follow:

$$
\tau=\tau_{0}+K \dot{\gamma}^{N},
$$

where: $\tau_{0}$ is yield stress, $K$ - consistency, $N$-dimensionless flow index behavior. Figure 9 presents both the experimental results and model (7) fitting. Herschel-Bulkley rheological parameters together with correlation coefficient, $\mathrm{R}^{2}$, were summarized in Table 6 .

Figure 9: Dependence of shear stress $(\tau)$, and dynamic viscosity $(\eta)$ on shear rate (flow and viscosity curves respectively) for ethylene glycol based nanofluids containing two types of carbon black nanoparticles at 298.15 K. Symbols represent measuring points collected with different concentration of nanoparticles, as follow: triangle $(\triangle, \mathbf{\Delta})-0.50 \mathrm{wt} . \%$, diamond $(\diamond, \diamond)-1.00 \mathrm{wt} . \%$, squares $(\square, \boldsymbol{\square})-2.00 \mathrm{wt} . \%$; solid (red) lines - results of the (7) model, dotted lines - pure ethylene glycol according to Ref. [61]. Empty and solid symbols refers to CB1-EG and CB2-EG nanofluids respectively.

Table 6: Herschel-Bulkley rheological parameters, $\tau_{0}, K, N$, determined on the base of flow curves presented in Fig. 9, of nanofluids containing two types of carbon black nanoparticles at $298.15 \mathrm{~K}$ and correlation coefficient, $\mathrm{R}^{2}$, of fitting.

\begin{tabular}{l|llll|llll} 
& \multicolumn{7}{c}{ CB1-EG } & \multicolumn{7}{|l}{ CB2-EG } \\
\hline$\varphi_{m}$ & $\tau_{0}$ & $K$ & $N$ & $\mathrm{R}^{2}$ & $\tau_{0}$ & $K$ & $N$ & $\mathrm{R}^{2}$ \\
- & $\mathrm{Pa}$ & $\mathrm{Pa} \mathrm{s}^{N}$ & - & - & $\mathrm{Pa}$ & $\mathrm{Pa} \mathrm{s}^{N}$ & - & - \\
\hline 0.005 & 0.12 & 0.047 & 0.90 & 0.99994 & 0.08 & 0.034 & 0.93 & 0.99995 \\
0.010 & 0.75 & 0.046 & 0.94 & 0.99905 & 0.31 & 0.045 & 0.90 & 0.99992
\end{tabular}




\begin{tabular}{lllll|llll}
0.020 & 3.70 & 0.153 & 0.91 & 0.97881 & 1.21 & 0.049 & 0.93 & 0.99969 \\
\hline
\end{tabular}

\subsection{Viscoelastic structure}

Non-Newtonian shear thinning behavior could indicate that these nanofluids has viscoelastic structure. In the series of oscillatory experiments at constant frequency $1 \mathrm{~Hz}$ both the storage (G') and the loss (G') moduli were determined in function of deformation. Results of this study have been presented in Fig. 10. It could be noted that the viscoelastic structure is fragile and G' starts decreasing at low deformation value (0.01). However a short linear viscoelastic region could be observed for the lowest examined deformations (up to 0.01). In this region both G' and G" are constant and could be calculated as an average in this deformation range. Results of such evaluation has been presented in Table 7 and shown as solid lines in Fig. 10.

Figure 10: Storage (G') and loss (G') moduli as a function of deformation $(\gamma)$ for various mass fractions of nanoparticles in ethylene glycol based nanofluids containing two types of carbon black nanoparticles at temperature $298.15 \mathrm{~K}$ and oscillation frequency of $1.0 \mathrm{~Hz}$. Symbols represent measuring points collected with different concentration of nanoparticles, as follow: triangle $(\triangle, \mathbf{\Delta})-0.50 \mathrm{wt} . \%$, diamond $(\diamond, \triangleleft)-1.00 \mathrm{wt} . \%$, squares $(\square, \mathbf{\square})-2.00 \mathrm{wt} . \%$; solid lines - average $\mathrm{G}^{\prime}$ and $\mathrm{G}$ " in the range of deformations from 0.001 to 0.01 . Empty and solid symbols refers to CB1-EG and CB2-EG nanofluids respectively.

Table 7: Values of storage (G'), loss (G") modulus of CB1-EG and CB2-EG nanofluids at 298.15 K. Values determined on the base of experimental results presented in Fig. 10 in region of deformation (lower than 0.010) where both G' and G' were constant.

\begin{tabular}{l|ll|ll} 
& CB1-EG & & CB2-EG & \\
\hline$\varphi_{m}$ & G' & G' & G' & G' \\
- & $\mathrm{Pa}$ & $\mathrm{Pa}$ & $\mathrm{Pa}$ & $\mathrm{Pa}$ \\
\hline 0.005 & 0.397 & 0.360 & 0.601 & 0.458 \\
0.010 & 23.004 & 2.585 & 5.717 & 1.449 \\
0.020 & 93.647 & 8.671 & 55.726 & 6.579 \\
\hline
\end{tabular}

Existence of the maximum in loss moduli observed for both examined nanofluids could be 
explained by the "overshoot phenomenon" as it was described in details by Pastoriza-Gallego et al. [62] and Hermida-Merino et al. [63].

\subsection{Refractive index}

Summary results of refractive index, $n$, measurements for examined ethylene glycol based carbon black nanofluids with different mass fractions of nanoparticles are shown in Fig. 11 and Table. 8. The refractive index of the studied nanofluids increases linearly with the mass fraction of the nanoparticles. The mathematical analysis carried out using the least squares fitting showed a correlation coefficient, $\mathrm{R}^{2}$, equal to 1 for both linear functions fitted experimental data. The linear dependence describing increase of the refractive index value for both examined types of nanofluids could be presented as:

$$
\begin{aligned}
& \frac{n_{n f}}{n_{b f}}=1+0.0914 \varphi_{m}, \\
& \frac{n_{n f}}{n_{b f}}=1+0.1410 \varphi_{m},
\end{aligned}
$$

where equation (8) refers to the CB1-EG and eq. (9) to CB2-EG nanofluids respectively.

Table 8: Experimental values of refractive index, $n_{n f}$, of CB-EG nanofluids at $298.15 \mathrm{~K}$.

\begin{tabular}{l|ll|ll} 
& CB1-EG & & CB2-EG & \\
\hline$\varphi_{m}$ & $n_{n f}$ & $n_{n f} / n_{b f}$ & $n_{n f}$ & $n_{n f} / n_{b f}$ \\
- & - & - & - \\
\hline 0.000 & 1.43028 & 1.0000 & 1.43028 & 1.0000 \\
0.005 & 1.43092 & 1.0004 & 1.43167 & 1.0010 \\
0.010 & 1.43138 & 1.0008 & 1.43238 & 1.0015 \\
0.020 & 1.43301 & 1.0019 & 1.43419 & 1.0027 \\
\hline
\end{tabular}

Figure 11: Dependence of refractive index, $n$, and refractive index ratio, $n_{n f} / n_{b f}$, on the mass fraction, $\varphi_{m}$, of the particles for the CB1-EG (o) and CB2-EG (•) nanofluids at 298.15 K. Points represent experimental data, dotted and solid line - linear function (8) and (9) respectively. 


\subsection{Electrical conductivity}

The electrical conductivity of two types of carbon black ethylene glycol based nanofluids was measured at $298.15 \mathrm{~K}$ and its results were presented in Fig. 12 and Table 9. The obtained results clearly indicate that both types of carbon black have impact on electrical properties of ethylene glycol. Increase in mass fraction (in whole examined range) of nanoparticles in EG causes enhancement of electrical conductivity for CB1-EG nanofluid as well as CB2-EG nanofluid. Observed changes in values of electrical conductivity for CB2-EG nanofluids are similar to those presented for ethylene glycol based nanofluids containing another carbon nanostructures (graphite/diamond with low ash content) presented elsewhere [22]. On the other hand electrical conductivity enhancement for CB1-EG nanofluids is high and according to the best authors knowledge it is the highest increase in electrical conductivity reported for nanofluids based on ethylene glycol for such low load of nanoparticles. The similar results in electrical conductivity enhancement of nanofluids was achieved for ethylene glycol with $7.5 \mathrm{wt} . \%$ silicon nitride nanoparticles $\left(\mathrm{Si}_{3} \mathrm{~N}_{4}\right)$ at $298.15 \mathrm{~K}$, which is almost four times higher mass fraction than used in this study. Such huge increase in electrical conductivity of CB1-EG nanofluids can be caused by extremely high specific surface area of used carbon black nanoparticles (Table 1) and creation of conduction path for fluids with higher content of CB1 as schematically shown in Fig. 13. For low mass fraction of nanoparticles in ethylene glycol, electrical conduction can increase by formation of electrical double layer (EDL) around nanoparticles [64]; for higher content of CB1, the conduction path can start to create.

Electrical conductivity enhancement of both type of CB-EG nanofluids can be described with good accuracy with the power function. It was found that results for CB1-EG nanofluids can be fitted by following equation (with $\mathrm{R}^{2}=0.97247$ ):

$$
\frac{\sigma_{n f}}{\sigma_{b f}}=1+1.62 \cdot 10^{7} \varphi_{m}^{1.73},
$$

and for CB2-EG nanofluids (with $\mathrm{R}^{2}=0.99999$ ):

$$
\frac{\sigma_{n f}}{\sigma_{b f}}=1+2.59 \cdot 10^{4} \varphi_{m}^{1.22} .
$$

Table 9: Experimental values of electrical conductivity, $\sigma_{n f}$, of CB-EG nanofluids at $298.15 \mathrm{~K}$. 


\begin{tabular}{l|ll|ll} 
& CB1-EG & & CB2-EG & \\
\hline$\varphi_{m}$ & $\sigma_{n f}$ & $\sigma_{p, n f} / \sigma_{p, b f}$ & $\sigma_{p, n f}$ & $\sigma_{p, n f} / \sigma_{p, b f}$ \\
- & $\mu \mathrm{S} \mathrm{cm}^{-1}$ & - & $\mu \mathrm{S} \mathrm{cm}^{-1}$ & - \\
\hline 0.000 & 0.21 & 1.00 & 0.21 & 1.00 \\
0.005 & 83.13 & 395.86 & 8.52 & 40.57 \\
0.010 & 1365.25 & 6501.19 & 19.73 & 93.95 \\
0.020 & 3941.79 & 18770.43 & 45.69 & 217.57 \\
\hline
\end{tabular}

Figure 12: Dependence of electrical conductivity, $\sigma$, and electrical conductivity ratio, $\sigma_{n f} / \sigma_{b f}$, on the mass fraction, $\varphi_{m}$, of the particles for the CB1-EG (०) and CB2-EG (•) nanofluids at 298.15 K. Points represent experimental data, dotted and solid line - functions (10) and (11) respectively.

Figure 13: Presentation of idea of creating conduction path in CB1-EG nanofluids. A) pure base fluid, B) nanofluid with low content of CB1, C) nanofluid with middle content of CB1, D) nanofluid with high content of CB1. Black dots present dispersed CB1 nanoparticles, red dots present creation of potential conduction path through dispersed CB1 nanoparticles.

\section{Conclusions}

The paper presents a comprehensive experimental characterization about thermal conductivity, isobaric heat capacity, mass density, nanofluid-air surface tension, dynamic viscosity and viscoelastic structure of ethylene glycol based nanofluids containing two types of carbon black nanoparticles. The electric properties like refractive index and electrical conductivity were also evaluated. This experimental study was performed at well controlled temperature 298.15 $\mathrm{K}$ and varying the mass content in $\mathrm{CB}$ nanoparticles up to $2 \mathrm{wt} . \%$.

It was presented that the specific surface area of particles in nanofluids has great influence on the fundamental physical properties. From the application point of view, the nanofluids containing nanoparticles with higher specific surface area seems to be more interesting according to their higher thermal conductivity and lower surface tension and isobaric heat capacity. On the other hand one must note that the dynamic viscosity increases significantly for these materials, 
which make it harder to apply in real-life heat exchanging systems.

The remarkable electrical conductivity enhancement reported in this paper (according to the best authors knowledge one of the highest reported in literature) in CB1-EG nanofluids could be interesting from the viewpoint of potential application of these materials in ink jet printed electronics, where currently expensive silver nanoparticles are used. More potential applications of the nanofluids with enhanced electrical conductivity could be found in recent review paper [8].

\title{
Acknowledgments
}

Research was partially supported by EU COST Action CA15119: Overcoming Barriers to Nanofluids Market Uptake and Rzeszow University of Technology grant no. UPB.FE.20.001. Additionally, authors acknowledge the financial support by Spanish "Ministerio de Economía, Industria y Competitividad" and EU FEDER programme through ENE2017-86425-C2-1-R project. JS acknowledges EU COST for the STSM grants ref. COST-STSM-CA15119-46214 and COST-STSM-CA15119-46737. JPV acknowledges FPI Program of "Ministerio de Economía y Competitividad". PE acknowledges the European Union through the European Regional Development Fund (ERDF), the Ministry of Higher Education and Research, the French region of Brittany and Rennes Métropole for the financial support related to the device used in this study for surface tension measurement. The authors wishes to thank M. Pasturel from Université Rennes 1 and B. Vigolo from IJL, Nancy for XRD experiments and analysis.

\section{Competing interests}

The authors declare that they have no competing interests.

\section{Declaration of interests}

\author{
The authors declare that they have no known competing financial \\ interests or personal relationships that could have appeared to \\ influence the work reported in this paper. \\ The authors declare the following financial interests/personal \\ relationships which may be considered as potential competing
}


interests:

Credit Author Statement

- Jolanta Sobczak: Investigation, Formal analysis, Writing - Original Draft,

- Javier P. Vallejo: Investigation, Formal analysis, Writing - Original Draft,

- Julian Traciak: Investigation, Formal analysis, Writing - Original Draft,

- Samah Hamze: Investigation, Formal analysis, Writing - Original Draft,

- Jacek Fal: Investigation, Formal analysis, Writing - Original Draft, - Patrice Estell'e: Conceptualization, Methodology, Formal analysis, Writing - Original Draft, Writing Review \& Editing,

- Luis Lugo: Conceptualization, Methodology, Formal analysis, Writing - Original Draft, Writing - Review \& Editing,

- Gawel 'Zyl a: Conceptualization, Methodology, Investigation, Formal analysis, Validation, Resources, Writing - Original Draft, Writing - Review \& Editing, Visualization, Supervision.

\section{References}

[1] H. Masuda, A. Ebata, K. Teramae, Alteration of thermal conductivity and viscosity of liquid by dispersing ultra-fine particles. dispersion of al2o3, sio2 and tio2 ultra-fine particles (1993).

[2] S. U. Choi, J. A. Eastman, Enhancing thermal conductivity of fluids with nanoparticles (10 
1995).

[3] L. Qiu, N. Zhu, Y. Feng, E. E. Michaelides, G. Żyła, D. Jing, X. Zhang, P. M. Norris, C. N. Markides, O. Mahian, A review of recent advances in thermophysical properties at the nanoscale: From solid state to colloids, Physics Reports 843 (2020) 1-81.

[4] P. Estellé, D. Cabaleiro, G. Żyła, L. Lugo, S. S. Murshed, Current trends in surface tension and wetting behavior of nanofluids, Renewable and Sustainable Energy Reviews 94 (2018) 931-944.

[5] O. Z. Sharaf, R. A. Taylor, E. Abu-Nada, On the colloidal and chemical stability of solar nanofluids: From nanoscale interactions to recent advances, Physics Reports 867 (2020) $1-84$.

[6] E. C. Okonkwo, I. Wole-Osho, I. W. Almanassra, Y. M. Abdullatif, T. Al-Ansari, An updated review of nanofluids in various heat transfer devices, Journal of Thermal Analysis and Calorimetry (2020) in press, doi: 10.1007/s10973-020-09760-2.

[7] J. Fal, O. Mahian, G. Żyła, Nanofluids in the service of high voltage transformers: breakdown properties of transformer oils with nanoparticles, a review, Energies 11 (11) (2018) 2942.

[8] A. A. Minea, A review on electrical conductivity of nanoparticle-enhanced fluids, Nanomaterials 9 (11) (2019) 1592.

[9] Y. Geng, H. Khodadadi, A. Karimipour, M. R. Safaei, T. K. Nguyen, A comprehensive presentation on nanoparticles electrical conductivity of nanofluids: Statistical study concerned effects of temperature, nanoparticles type and solid volume concentration, Physica A: Statistical Mechanics and its Applications 542 (2020) 123432.

[10] H. Khodadadi, S. Aghakhani, H. Majd, R. Kalbasi, S. Wongwises, M. Afrand, A comprehensive review on rheological behavior of mono and hybrid nanofluids: effective parameters and predictive correlations, International Journal of Heat and Mass Transfer 127 (2018) 997-1012.

[11] B. Jóźwiak, S. Boncel, Rheology of ionanofluids-a review, Journal of Molecular Liquids 302 (2020) 112568.

[12] M. S. Sadeghi, N. Anadalibkhah, R. Ghasemiasl, T. Armaghani, A. S. Dogonchi, A. J. Chamkha, H. Ali, A. Asadi, On the natural convection of nanofluids in diverse shapes of enclosures: an exhaustive review, Journal of Thermal Analysis and Calorimetry in press, 
DOI: 10.1007/s10973-020-10222-y (2020) 1-22.

[13] S. Murshed, M. Sharifpur, S. Giwa, J. P. Meyer, Experimental research and development on the natural convection of suspensions of nanoparticles-a comprehensive review, Nanomaterials 10 (9) (2020) 1855.

[14] N. Trong Tam, N. Viet Phuong, P. Hong Khoi, P. Ngoc Minh, M. Afrand, P. Van Trinh, B. Hung Thang, G. Żyła, P. Estellé, Carbon nanomaterial-based nanofluids for direct thermal solar absorption, Nanomaterials 10 (6) (2020) 1199.

[15] F. Mashali, E. M. Languri, J. Davidson, D. Kerns, W. Johnson, K. Nawaz, G. Cunningham, Thermo-physical properties of diamond nanofluids: A review, International Journal of Heat and Mass Transfer 129 (2019) 1123-1135.

[16] N. A. C. Sidik, M. N. A. W. M. Yazid, S. Samion, A review on the use of carbon nanotubes nanofluid for energy harvesting system, International Journal of Heat and Mass Transfer 111 (2017) 782-794.

[17] A. Kotia, K. Chowdary, I. Srivastava, S. K. Ghosh, M. K. A. Ali, Carbon nanomaterials as friction modifiers in automotive engines: Recent progress and perspectives, Journal of Molecular Liquids (2020) 113200.

[18] M. Shamaeil, M. Firouzi, A. Fakhar, The effects of temperature and volume fraction on the thermal conductivity of functionalized dwcnts/ethylene glycol nanofluid, Journal of Thermal Analysis and Calorimetry 126 (3) (2016) 1455-1462.

[19] P. Van Trinh, N. N. Anh, N. T. Hong, P. N. Hong, P. N. Minh, B. H. Thang, Experimental study on the thermal conductivity of ethylene glycol-based nanofluid containing gr-cnt hybrid material, Journal of Molecular Liquids 269 (2018) 344-353.

[20] S. Harish, K. Ishikawa, E. Einarsson, S. Aikawa, S. Chiashi, J. Shiomi, S. Maruyama, Enhanced thermal conductivity of ethylene glycol with single-walled carbon nanotube inclusions, International Journal of heat and mass transfer 55 (13-14) (2012) 3885-3890.

[21] W. Yu, H. Xie, Y. Li, L. Chen, Q. Wang, Experimental investigation on the thermal transport properties of ethylene glycol based nanofluids containing low volume concentration diamond nanoparticles, Colloids and Surfaces A: Physicochemical and Engineering Aspects 380 (1-3) (2011) 1-5.

[22] G. Żyła, J. Fal, P. Estellé, The influence of ash content on thermophysical properties of ethylene glycol based graphite/diamonds mixture nanofluids, Diamond and Related 
Materials 74 (2017) 81-89.

[23] C. Selvam, S. Harish, D. M. Lal, Effective thermal conductivity and rheological characteristics of ethylene glycol-based nanofluids with single-walled carbon nanohorn inclusions, Fullerenes, Nanotubes and Carbon Nanostructures 25 (2) (2017) 86-93.

[24] G. Żyła, Nanofluids containing low fraction of carbon black nanoparticles in ethylene glycol: An experimental study on their rheological properties, Journal of Molecular Liquids 297 (2020) 111732.

[25] A. Mariano, M. J. Pastoriza-Gallego, L. Lugo, A. Camacho, S. Canzonieri, M. M. Piñeiro, Thermal conductivity, rheological behaviour and density of non-newtonian ethylene glycol-based sno2 nanofluids, Fluid phase equilibria 337 (2013) 119-124.

[26] M. Pastoriza-Gallego, L. Lugo, D. Cabaleiro, J. Legido, M. Piñeiro, Thermophysical profile of ethylene glycol-based zno nanofluids, The Journal of Chemical Thermodynamics 73 (2014) 23-30.

[27] A. Mariano, M. J. Pastoriza-Gallego, L. Lugo, L. Mussari, M. M. Piñeiro, Co3o4 ethylene glycol-based nanofluids: thermal conductivity, viscosity and high pressure density, International Journal of Heat and Mass Transfer 85 (2015) 54-60.

[28] D. Cabaleiro, C. Gracia-Fernández, J. Legido, L. Lugo, Specific heat of metal oxide nanofluids at high concentrations for heat transfer, International journal of heat and mass transfer 88 (2015) 872-879.

[29] G. Żyła, J. P. Vallejo, L. Lugo, Isobaric heat capacity and density of ethylene glycol based nanofluids containing various nitride nanoparticle types: An experimental study, Journal of Molecular Liquids 261 (2018) 530-539.

[30] G. Żyła, J. P. Vallejo, J. Fal, L. Lugo, Nanodiamonds-ethylene glycol nanofluids: Experimental investigation of fundamental physical properties, International Journal of Heat and Mass Transfer 121 (2018) 1201-1213.

[31] G. Żyła, J. Fal, P. Estellé, Thermophysical and dielectric profiles of ethylene glycol based titanium nitride (tin-eg) nanofluids with various size of particles, International Journal of Heat and Mass Transfer 113 (2017) 1189-1199.

[32] M. Moosavi, E. K. Goharshadi, A. Youssefi, Fabrication, characterization, and measurement of some physicochemical properties of zno nanofluids, International journal of heat and fluid flow 31 (4) (2010) 599-605. 
[33] M. Wanic, D. Cabaleiro, S. Hamze, J. Fal, P. Estellé, G. Żyła, Surface tension of ethylene glycol-based nanofluids containing various types of nitrides, Journal of Thermal Analysis and Calorimetry 139 (2) (2020) 799-806.

[34] A. Asadi, F. Pourfattah, I. M. Szilágyi, M. Afrand, G. Żyła, H. S. Ahn, S. Wongwises, H. M. Nguyen, A. Arabkoohsar, O. Mahian, Effect of sonication characteristics on stability, thermophysical properties, and heat transfer of nanofluids: A comprehensive review, Ultrasonics sonochemistry 58 (2019) 104701.

[35] W. Yu, H. Xie, L.-H. Liu, A review on nanofluids: Preparation, stability mechanisms, and applications, Journal of Nanomaterials 2012 (711) (2011) 128.

[36] D. Cabaleiro, S. Hamze, J. Fal, M. A. Marcos, P. Estellé, G. Żyła, Thermal and physical characterization of peg phase change materials enhanced by carbon based nanoparticles, Nanomaterials 10 (6) (2020) 1168.

[37] A. Banisharif, M. Aghajani, S. Van Vaerenbergh, P. Estellé, A. Rashidi, Thermophysical properties of water ethylene glycol (weg) mixture-based fe3o4 nanofluids at low concentration and temperature, Journal of Molecular Liquids 302 (2020) 112606.

[38] S. Zeroual, P. Estellé, D. Cabaleiro, B. Vigolo, M. Emo, W. Halim, S. Ouaskit, Ethylene glycol based silver nanoparticles synthesized by polyol process: Characterization and thermophysical profile, Journal of Molecular Liquids (2020) 113229.

[39] A. D7896-19, Standard test method for thermal conductivity, thermal diffusivity, and volumetric heat capacity of engine coolants and related fluids by transient hot wire liquid thermal conductivity method, ASTM International www.astm.org (2019).

[40] J. Vallejo, J. Pérez-Tavernier, D. Cabaleiro, J. Fernández-Seara, L. Lugo, Potential heat transfer enhancement of functionalized graphene nanoplatelet dispersions in a propylene glycol-water mixture. thermophysical profile, The Journal of Chemical Thermodynamics 123 (2018) 174-184.

[41] F. Steckel, S. Szapiro, Physical properties of heavy oxygen water. part 1. density and thermal expansion, Transactions of the Faraday Society 59 (1963) 331-343.

[42] G. Żyła, J. Fal, Experimental studies on viscosity, thermal and electrical conductivity of aluminum nitride-ethylene glycol (aln-eg) nanofluids, Thermochimica Acta 637 (2016) $11-16$.

[43] G. Żyła, J. Fal, S. Bikić, M. Wanic, Ethylene glycol based silicon nitride nanofluids: An 
experimental study on their thermophysical, electrical and optical properties, Physica E: Low-dimensional Systems and Nanostructures 104 (2018) 82-90.

[44] D. R. Lide, CRC handbook of chemistry and physics, Vol. 85, CRC press, 2004.

[45] S. Akilu, A. T. Baheta, A. A. Minea, K. Sharma, Rheology and thermal conductivity of non-porous silica (sio2) in viscous glycerol and ethylene glycol based nanofluids, International Communications in Heat and Mass Transfer 88 (2017) 245-253.

[46] M. P. Beck, Y. Yuan, P. Warrier, A. S. Teja, The effect of particle size on the thermal conductivity of alumina nanofluids, Journal of Nanoparticle research 11 (5) (2009) 1129-1136.

[47] M. Mehrali, E. Sadeghinezhad, S. T. Latibari, S. N. Kazi, M. Mehrali, M. N. B. M. Zubir, H. S. C. Metselaar, Investigation of thermal conductivity and rheological properties of nanofluids containing graphene nanoplatelets, Nanoscale research letters 9 (1) (2014) 15.

[48] M. Mehrali, E. Sadeghinezhad, M. A. Rosen, S. T. Latibari, M. Mehrali, H. S. C. Metselaar, S. N. Kazi, Effect of specific surface area on convective heat transfer of graphene nanoplatelet aqueous nanofluids, Experimental thermal and fluid science 68 (2015) 100-108.

[49] G.-J. Lee, C. K. Rhee, Enhanced thermal conductivity of nanofluids containing graphene nanoplatelets prepared by ultrasound irradiation, Journal of Materials Science 49 (4) (2014) 1506-1511.

[50] E. V. Timofeeva, D. S. Smith, W. Yu, D. M. France, D. Singh, J. L. Routbort, Particle size and interfacial effects on thermo-physical and heat transfer characteristics of water-based $\alpha$-sic nanofluids, Nanotechnology 21 (21) (2010) 215703.

[51] O. A. Alawi, N. A. C. Sidik, H. W. Xian, T. H. Kean, S. N. Kazi, Thermal conductivity and viscosity models of metallic oxides nanofluids, International Journal of Heat and Mass Transfer 116 (2018) 1314-1325.

[52] P. Nikolaev, I. Rabinovich, Heat capacity of ethylene glycol and ethylene deuteroglycol in the temperature range 80-300k, Zhur. Fiz. Khim 41 (1967) 2191-2194.

[53] S. SV, et al., Behaviour of excess heat capacity of aqueous non-electrolytes., Indian J. Pure Appl. Phys. 15 485-489.

[54] M. A. Stephens, W. S. Tamplin, Saturated liquid specific heats of ethylene glycol homologs, Journal of Chemical and Engineering Data 24 (2) (1979) 81-82. 
[55] Z. Zaripov, Experimental study of the isobaric heat capacity of liquid organic compounds with molecular weights of up to 4000, Teplomassoobmen Teplofiz (1982).

[56] H. Riazi, T. Murphy, G. B. Webber, R. Atkin, S. S. M. Tehrani, R. A. Taylor, Specific heat control of nanofluids: A critical review, International Journal of Thermal Sciences 107 (2016) 25-38.

[57] Y. Xuan, W. Roetzel, Conceptions for heat transfer correlation of nanofluids, International Journal of heat and Mass transfer 43 (19) (2000) 3701-3707.

[58] Y. Takahashi, E. F. Westrum Jr, Glassy carbon low-temperature thermodynamic properties, The Journal of Chemical Thermodynamics 2 (6) (1970) 847-854.

[59] A. Lutcov, V. Volga, B. Dymov, Thermal conductivity, electric resistivity and specific heat of dense graphites, Carbon 8 (6) (1970) 753-760.

[60] J. Chinnam, D. K. Das, R. S. Vajjha, J. R. Satti, Measurements of the surface tension of nanofluids and development of a new correlation, International Journal of Thermal Sciences 98 (2015) 68-80.

[61] G. Żyła, Thermophysical properties of ethylene glycol based yttrium aluminum garnet (y3al5o12-eg) nanofluids, International Journal of Heat and Mass Transfer 92 (2016) $751-756$.

[62] M. J. Pastoriza-Gallego, L. Lugo, J. L. Legido, M. M. Piñeiro, Rheological non-newtonian behaviour of ethylene glycol-based fe 2 o 3 nanofluids, Nanoscale research letters 6 (1) (2011) 560 .

[63] C. Hermida-Merino, M. Pérez-Rodríguez, M. M. Piñeiro, M. J. Pastoriza-Gallego, Evidence of viscoplastic behavior of exfoliated graphite nanofluids, Soft Matter 12 (8) (2016) 2264-2275.

[64] E. I. Chereches, A. A. Minea, Electrical conductivity of new nanoparticle enhanced fluids: An experimental study, Nanomaterials 9 (9) (2019) 1228.

Highlights

- $\quad$ Two types of carbon black nanoparticles were used in EG based nanofluids.

- - Thermal conductivity, heat capacity, mass density, surface tension were examined.

- Electrical conductivity and refractive index were investigated as well.

- - Flow and viscosity curves were presented with Herschel-Bulkley model fitting.

- Specific surface area of particles influence the physical properties of nanofluids 